\title{
h० ${ }^{\perp}$
}

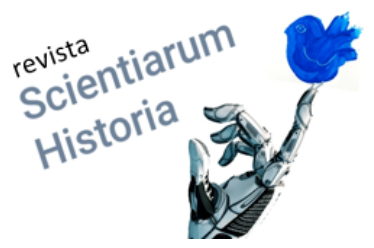

\section{Celso Furtado: planning and overcoming underdevelopment (1950-1964)}

\section{Celso Furtado: planejamento e superação do subdesenvolvimento (1950-1964)}

\author{
Wilson Vieira \\ Laboratório de Estudos Marxistas, Laboratório de Estudos sobre Hegemonia e \\ Contra-Hegemonia, Instituto de Economia, Universidade Federal do Rio de Janeiro \\ vieiraeco@gmail.com,wilson.vieira@ie.ufrj.br
}

Recebido: 27/04/2021 Aceito: 29/04/2021 Publicado: 04/05/2021

DOI: $10.51919 /$ revista_sh.v1i0.265

\begin{abstract}
This article has as its object the Celso Furtado's reflection and performance in favor of overcoming underdevelopment through the technique of global planning between 1950 and 1964. The objectives are: 1) to show how Furtado acts and reflects on democratic global planning; 2) to analyze the relationship between technique and politics in this performance and in this reflection; 3) to present the continuities and changes in his performance as a planner at the Economic Commission for Latin America and the Caribbean (ECLAC), at the Superintendence for the Development of the Northeast (SUDENE) and at the Ministry of Planning. The justification for choosing the 1950-1964 time cut can be found in the fact that it was the period in which Furtado acted most directly in planning.
\end{abstract}

Password. Economics. Celso Furtado. Overcoming underdevelopment.

Resumo. Este artigo tem como objeto a reflexão e a atuação de Celso Furtado em prol da superação do subdesenvolvimento através da técnica do planejamento global entre 1950 e 1964. Os objetivos são: 1) mostrar como Furtado atua e reflete sobre o planejamento global democrático; 2) analisar a relação entre técnica e política nessa atuação e nessa reflexão; 3) apresentar as continuidades e mudanças na sua atuação como planejador na Comissão Econômica para a América Latina e o Caribe (CEPAL), na Superintendência para o Desenvolvimento do Nordeste (SUDENE) e no Ministério do Planejamento. A justificativa da escolha do corte temporal 1950-1964 pode ser encontrada no fato de que foi o período em que Furtado atuou mais diretamente como planejador.

Palavras-chave. Economia. Celso Furtado. Superação do subdesenvolvimento. 


\section{Introdução}

O objeto deste artigo é a reflexão e a atuação de Celso Furtado (1920-2004) em prol da superação do subdesenvolvimento através do planejamento global democrático entre 1950 e 1964.

Os objetivos são: 1) mostrar como Furtado atua e reflete sobre o planejamento global democrático; 2) analisar a relação entre técnica e política nessa atuação e nessa reflexão; 3) apresentar as continuidades e mudanças na sua atuação como planejador na Comissão Econômica para a América Latina e o Caribe (CEPAL), na Superintendência para o Desenvolvimento do Nordeste (SUDENE) e no Ministério do Planejamento.

A hipótese de trabalhoé a de que Furtado, fortemente influenciado por Karl Mannheim, teórico do planejamento democrático, viveu fortemente a tensão/contradição do planejador estatal técnico membro da intelligentsia acima das discussões político-partidárias que teve que fazer muita política a fim de que o tipo de planejamento que defendia pudesse ter espaço no Brasil, especialmente no período em que atuou na SUDENE.

A justificativa da escolha do corte temporal 1950-1964 pode ser encontrada no fato de que foi o período em que Furtado atuou mais diretamente como planejador.

Além desta introdução, o trabalho está dividido da seguinte maneira: na segunda seção expomos brevemente a teoria do planejamento democrático de Karl Mannheim, grande influenciador de Furtado nessa temática; na terceira seção analisamos a atuação e a reflexão de Furtado sobre o planejamento durante o período em que foi quadro da CEPAL; na quarta seção fazemos o mesmo tipo de análise da seção anterior, mas desta vez durante o período em que Furtado atuou na SUDENE e no Ministério do Planejamento; nas conclusões fazemos uma breve sistematização da discussão e tecemos breves considerações finais.

\section{O planejamento democrático de Karl Mannheim}

Na busca pela superação do subdesenvolvimento, Furtado na sua atuação e reflexão defende um planejamento global democrático com vistas à industrialização sob a liderança do Estado. Tal planejamento é fortemente influenciado por Karl Mannheim (1896-1947), sociólogo alemão do conhecimento e elaborador da ideia de planejamento democrático ${ }^{1}$, no qual estão presentes os seguintes elementos:

I) Utilização de técnicas sociais baseadas em estudos científicos da sociedade, conjugados, se possível, com a experiência sociológica.

II) Controle democrático dos planejadores num sistema parlamentar o qual garante a rotação das elites líderes (pelo menos na esfera política) e previne a manipulação das massas.

\footnotetext{
${ }^{1} \mathrm{~A}$ ideia de planejamento democrático de Mannheim encontra-se exposta nos livros O Homem e a Sociedade (1962 [1940]) e Liberdade, Poder e Planificação Democrática (1972 [1951]).
} 
III) Os planejadores, membros da intelligentsia, são colocados acima das disputas político-partidárias, ocupando uma posição chave na mudança social como “especialistas na invenção e na difusão das ideias" (MANNHEIM, 1972: 86) ${ }^{2}$, iniciando o processo que pode conduzir a sociedade no caminho da planificação para a liberdade. Portanto, na visão de Mannheim, o planejamento democrático conta com a participação da sociedade, mas é iniciado pelos planificadores, membros da intelligentsia, colocada acima das disputas da sociedade, como se nela não estivesse inserida, configurando para nós em uma contradição a qual foi vivida por Furtado, como analisamos nos próximos itens.

\section{Furtado e o planejamento na CEPAL (1950-1958)}

No período em que atuou na CEPAL (1950-1958), além das reflexões sobre a constituição histórica do subdesenvolvimento brasileiro, aprofundando o que havia desenvolvido em sua tese de doutorado (defendida em 1948) ${ }^{3}$, Furtado reflete e atua em busca da superação de tal situação através da industrialização planejada pelo Estado. Cabe destacar nesse período a sua participação no Grupo Misto BNDE -CEPAL (1953-1955), tomando parte de um rico debate sobre o planejamento, defendendo aquele proposto pela CEPAL, de tipo global, no sentido contrário às posições de Eugênio Gudin e Octávio Gouvêa de Bulhões, que eram críticos de tal tipo de planejamento, visto por eles como inflacionário, defendendo, ao contrário, uma planificação focada (somente em setores específicos de acordo com suas necessidades).

O planejamento global para Furtado (1953, 1954b, 1956b, 1958a, 1958b) é um dos caminhos para alcançar o desenvolvimento econômico, consistindo na coordenação e intensificação dos investimentos a partir do Estado e numa política encaminhada a lograr a racionalização do uso dos recursos humanos e materiais que a economia tem à sua disposição, observando-a na sua totalidade. Essa técnica de planejamento utilizada pela CEPAL e proposta aos países da América Latina, tem o seguinte procedimento: inicia com estudos preliminares baseados numa análise de conjunto do processo econômico, elabora uma primeira etapa do plano, e, após tal elaboração, determina os critérios de substituição de importações a partir da formulação de hipóteses sobre as importações que por sua vez dependem do conhecimento das metas de produção interna. Ou seja, um círculo que reflete a necessidade de um ajustamento final no plano. A técnica utilizada nesse tipo de planejamento, segundo o economista, é sempre neutra, pois pode reforçar ou debilitar a posição da empresa privada como organizadora do sistema produtivo.

Observamos que Furtado, na defesa do planejamento global como elemento de superação do subdesenvolvimento, utiliza uma argumentação na qual coloca a técnica "acima" da política. Mesmo em questões como a defesa de distribuição de renda mais

\footnotetext{
${ }^{2}$ Segundo Cepêda (2008: 370): “A intelligentsia de Mannheim é pragmática, portanto, tem interface com a política, mas não é meio de realização de interesses setoriais e/ou partidários - deve ser objetiva e neutra, e não objetiva e absenteísta".

${ }^{3}$ A tese foi publicada em português em 2001. Os desdobramentos da tese podem ser observados em Furtado (1950, 1954a, 1956a, 2007 [1959]).

${ }^{4}$ Banco Nacional de Desenvolvimento Econômico.
} 
igualitária dentro do planejamento global, os argumentos técnicos é que dão a tônica, dentro da visão mannheimiana da intelligentsia acima das discussões político-partidárias, da qual a CEPAL mantinha atitudes semelhantes.

Devido à posição que ocupava na CEPAL, um órgão da $\mathrm{ONU}^{5}$ que limitava as manifestações políticas de seus membros, Furtado, nesse debate, possui uma preocupação em ressaltar os argumentos técnicos, não deixando registrada em nenhum momento a questão da democracia nesse processo, somente no período em que atua na SUDENE e brevemente no Ministério do Planejamento, como observamos no próximo item.

\section{Furtado e o planejamento na SUDENE (1959-1964)}

Após sua atuação no Grupo Misto BNDE-CEPAL, Furtado retorna à sede da CEPAL em Santiago (Chile), onde permanece até 1958, quando se licencia para permanecer nesse ano na Universidade de Cambridge, pesquisando e escrevendo um dos seus principais livros - Formação Econômica do Brasil -, lançado em 1959. Ainda em 1958 retorna ao Brasil (já não mais como membro da CEPAL) para assumir um posto no BNDE e intervir no Grupo de Trabalho para o Desenvolvimento do Nordeste (GTDN), a fim de saber o motivo de não ter nenhum trabalho concluído até aquele momento. De maneira independente, Furtado organiza um trabalho particular de coleta de dados e processamento de informações, inclusive com uma viagem ao Nordeste, onde observa as péssimas condições do quadro social e as disputas por verbas do Governo Federal aplicadas na região. Conjuntamente a essa pesquisa de campo, Furtado teve acesso a trabalhos que técnicos da ONU haviam feito para o BNDE sobre o Nordeste, e também a estudos sobre o Nordeste realizados por brasileiros e percebe, tal como ocorrera com os pesquisadores estrangeiros, que eram focados, sem visão global dos problemas da região.

Furtado faz o relato desse caminho no GTDN, mas não descreve nada sobre o resultado desse trabalho particular em A Fantasia Desfeita (1989), mas é muito grande a possibilidade dele ter sido aproveitado, mesmo incompleto, para a sua argumentação em defesa de uma política de desenvolvimento para o Nordeste numa reunião realizada no Palácio Rio Negro (Petrópolis) em 6 de janeiro de 1959, convocada pelo Presidente Juscelino Kubitschek, da qual resultou na criação da Operação Nordeste, cuja liderança ficou a cargo do economista por designação presidencial, e que, para sua implementação, contou com as ações listadas abaixo.

1) Elaboração de um estudo que compreende um diagnóstico e um plano de ação que se constitui no documento do GTDN - Uma Política de Desenvolvimento Econômico para o Nordeste - o qual acreditamos ser uma versão mais completa e aprofundada daquele estudo particular que mencionamos acima. Em termos gerais, o documento expõe a situação de atraso do Nordeste em relação ao Centro-Sul e propõe um Plano de Ação com quatro diretrizes: a) intensificação dos investimentos industriais com o objetivo de

\footnotetext{
${ }^{5}$ Sobre as dificuldades que Furtado enfrentou para expressar suas posições em seus trabalhos enquanto membro da CEPAL, ver Furtado (1985: 183) e Dosman (2011: 368).
} 
criar um centro autônomo de expansão manufatureira; b) transformação da economia agrícola da faixa úmida a fim de proporcionar uma oferta adequada de alimentos nos centros urbanos, cuja industrialização deverá ser intensificada; c) transformação progressiva da economia das zonas semiáridas no sentido de elevar sua produtividade e torná-la mais resistente ao impacto das secas; d) deslocamento da fronteira agrícola do Nordeste, a fim de incorporar à economia da região as terras úmidas do hinterland maranhense, que estão em condições de receber os excedentes populacionais criados pela reorganização da economia da faixa semiárida.

2) Definição de imediato da estratégia com o objetivo de mobilizar forças de apoio e reorientar a ação do governo federal na região.

3) Conversas com políticos e "chefes regionais".

Na Operação Nordeste percebemos a atuação política do técnico para se dedicar à sua parte na tarefa de superar o quadro de atraso do Nordeste em relação ao Centro-Sul, não somente na articulação com os políticos, mas também com a opinião pública em geral (cf. FURTADO, 1989: 51), isto é, uma ação com uma roupagem técnica, mas que possui uma visão política que a sustenta, mesmo procurando seguir a ideia de Mannheim acerca do papel da intelligentsia, que está acima das discussões partidárias, denotando em Furtado o reflexo da contradição do sociólogo alemão, posto que ele precisou desde o início fazer política para poder implementar os planos e as ações de superação do subdesenvolvimento nordestino. E mais: tal atuação coloca em xeque inclusive a defesa de uma técnica neutra utilizada no planejamento global, tal como observamos no item anterior. Portanto, Furtado continua defendendo o planejamento democrático, mas agora, de forma mais explícita, tanto na sua atuação como na sua reflexão (como observamos mais à frente).

O lançamento oficial da Operação Nordeste ocorreu em março de 1959 no Palácio do Catete (Rio de Janeiro), durante o qual foi oficializada a criação do Conselho de Desenvolvimento do Nordeste (CODENO) e a assinatura da mensagem ao Congresso Nacional, propondo a criação da SUDENE, que teria o objetivo de implementar as políticas de desenvolvimento para essa região e cujas atribuições ficariam a cargo do CODENO enquanto a instituição da superintendência não fosse autorizada pelo Parlamento. Ambos os órgãos seriam liderados por Celso Furtado. Foi nesse lançamento que Furtado expôs o documento do GTDNpara fundamentar sua proposta.

A partir da instalação do CODENO em 25 de abril de 1959, começa uma longa batalha para a SUDENE ser aprovada. O intelectual e técnico Furtado se vê obrigado a buscar amplo apoio na opinião pública do Centro-Sul, pois os postos de liderança no Congresso eram com frequência ocupados por nordestinos opositores a esse projeto e que fariam de tudo para barrar a criação desse órgão, pois ia contra seus interesses de manutenção de poder regional.

Com a aprovação da SUDENE em 15 de dezembro de 1959, Furtado dá à instituição um tom marcadamente técnico, mas sem deixar de buscar apoio na opinião pública, refletindo, como afirmamos anteriormente, a contradição de Mannheim. E no período 
de atuação nesse órgão, enfrentou muitas dificuldades para levar à frente seus projetos devido à forte oposição da direita e dos EUA.

Além da atuação pela SUDENE, destacamos sua breve participação como ministro no então recém-criado Ministério Extraordinário do Planejamento, a partir de um convite feito pelo Presidente João Goulart (1918-1976) em fins de setembro de 1962, a fim de elaborar um plano de governo, dada a grande probabilidade do presidencialismo ser restaurado no plebiscito de 6 de janeiro de 1963, o que de fato ocorreu.

O plano de governo, denominado Plano Trienal, tinha os seguintes objetivos fundamentais (cf. PLANO TRIENAL, 2011 [1962]: 43-44):

1) Taxa de crescimento da renda nacional em torno de $7 \%$ ao ano (correspondente a $3,9 \%$ de crescimento da renda per capita).

2) Redução progressiva da inflação.

3) Criação de condições para que os frutos do desenvolvimento se distribuam de maneira cada vez mais ampla pela população, cujos salários reais devem crescer com uma taxa pelo menos igual à do aumento da produtividade do conjunto da economia, além dos ajustamentos decorrentes do aumento do custo de vida.

4) Intensificação substancial da ação do governo na educação, na pesquisa científica e tecnológica e na saúde pública a fím de promover uma rápida melhoria do ser humano como fator de desenvolvimento e de permitir o acesso de uma parte crescente da população aos frutos do progresso cultural.

5) Orientação adequada do levantamento dos recursos naturais e localização da atividade econômica com o objetivo de desenvolver as distintas áreas do país e reduzir as disparidades regionais de níveis de vida, mas sem o aumento do custo social do desenvolvimento.

6) Eliminação progressiva dos entraves de ordem institucional (como a estrutura agrária), vistos como responsáveis pelo desgaste dos fatores de produção e pela lenta assimilação de novas técnicas em determinados setores produtivos.

7) Refinanciamento adequado da dívida externa, além de evitar a piora do endividamento brasileiro no exterior.

8) Assegurar, por parte do governo, uma crescente unidade de comando dentro de uma esfera própria de ação, na qual as suas distintas agências se submetam às diretrizes do plano.

Portanto, é um plano dentro da ideia de planejamento global, tal como o economista fez no período em que coordenou o Grupo Misto BNDE-CEPAL e também dentro de uma linha de planejamento democrático, como observamos em Furtado (1989):

\footnotetext{
Mantinha-me em contato direto com todas as equipes e multiplicava as entrevistas externas: debates com associações de classes, diálogos com grupos políticos, recepção de um sem-número de pessoas que, com ou sem razão, se consideravam no direito de opinar sobre o que devia ou não ser o tal plano de governo em preparação. E tudo isso se desenvolvia em meio a uma apaixonada campanha eleitoral, primeiro para eleger governadores e parlamentares, e em seguida para plebiscitar o parlamentarismo.(FURTADO, $1989 ;$ p.154-155)
} 
Em termos concretos, o plano mal saiu do papel porque Furtado retornou à SUDENE devido à sua exoneração do cargo de ministro (juntamente com todo o ministério) por pressões políticas sofridas por Goulart, numa conjuntura de grande instabilidade social e política.

As reflexões sobre o planejamento democrático feitas por Furtado nesse período podem ser encontradas no livro A Pré-Revolução Brasileira (1962), no qual analisamos alguns capítulos que tratam desse tema mais especificamente.

No primeiro capítulo - Reflexões sobre a Pré-Revolução Brasileira - Furtado deixa explícito que os países ocidentais desenvolvidos possuem um modelo que nos mostra a possibilidade de promover o desenvolvimento econômico via planejamento estatal com democracia, mas fazendo adaptações à nossa realidade. Segundo Furtado (1962: 32):

\begin{abstract}
Os problemas mais complexos devem ser objeto de estudos sistemáticos por grupo de especialistas, devendo as conclusões ser objeto de debate geral. $\mathrm{O}$ país está maduro para começar a refletir sobre seu próprio destino. Dos debates gerais e das manifestações da opinião pública deverão surgir as plataformas que servirão de base à renovação da representação popular.(FURTADO, 1962; p.32)
\end{abstract}

No terceiro capítulo - O Problema do Nordeste - cabe destacar o diagnóstico da situação nordestina vis-à vis o Centro-Sul e a defesa da atuação da SUDENE como órgão técnico para enfrentar os problemas dessa região através do planejamento democrático, mas sem deixar explícita tal expressão, mostrando somente a importância do planejamento estatal debatido com o povo.

No quinto capítulo - Subdesenvolvimento e Estado Democrático- o autor coloca a necessidade do planejamento numa economia subdesenvolvida como a brasileira. E este planejamento não significa autoritarismo e nem supressão das liberdades individuais os países desenvolvidos mostram bem isso, segundo ele. E para que o planejamento se faça é necessário o aparelhamento do Estado, o que ainda não tinha ocorrido, apesar de iniciativas positivas no período. Ou seja, o Estado ainda não estava devidamente aparelhado para exercer nenhuma das funções básicas de uma política de desenvolvimento econômico e por isso Furtado defende a importânciada preparação de quadros, além de um maior entrosamento entre especialistas em ciências políticas e administrativas e economistas, visto ser condição indispensável ao êxito da política de desenvolvimento e reconstrução do país.

\title{
5. Conclusões
}

Como forma de sistematização desta discussão, podemos afirmar que Furtado, sob forte influência de Mannheim, defende na sua atuação e na sua reflexão o planejamento global democrático.

No período em que atua na CEPAL, a defesa se dá em torno do planejamento global, visto por esse órgão da ONU como o melhor caminho para promover a industrialização e superar o subdesenvolvimento. É um momento em que não há menção à questão da 
democracia nesse processo, dada a sua situação de membro da CEPAL com os argumentos técnicos enfatizados, defendendo, inclusive a neutralidade da técnica ao mencionar que tal tipo de planejamento pode reforçar ou debilitar a posição da empresa privada no processo produtivo, em um processo em que a técnica se coloca "acima" da política. Na prática, porém, a técnica não é neutra, pois ela é também uma opção política ao observarmos o planejamento nos países socialdemocratas, modelo de Furtado.

No período em que atua pela SUDENE, fica mais explícita a sua atuação em favor do planejamento democrático, sem deixar de defendê-lo como global, observando a economia e a sociedade como um todo a fim de se conseguir superar a situação de subdesenvolvimento. Nesse percurso, podemos constatar que Furtado vive a contradição de Mannheim, pois, ao mesmo tempo em que se coloca como o intelectual, membro da intelligentsia, planejador estatal acima das disputas político-partidárias, o técnico tem que fazer muita política para a SUDENE poder atuar de forma técnica, o mesmo se dando na sua breve atuação no Ministério do Planejamento quando elaborou o Plano Trienal.

Portanto, no período analisado da atuação e da reflexão de Furtado sobre o planejamento, fica demonstrada a não neutralidade da técnica e do técnico que se insere no debate político, pois ambos não se encontram "acima" da política e são, na verdade, frutos de opções político-ideológicas, dado que a opção ou não pela democracia, a ênfase ou não na atuação da empresa privada ou na empresa estatal no planejamento, a defesa do planejamento global, são frutos dessas opções.

\section{Referências}

CEPÊDA, V. A. O lugar da teoria do subdesenvolvimento de Celso Furtado no pensamento político dos anos 1950. In: BOTELHO, André; BASTOS, Elide Rugai; VILLAS BÔAS, Glaucia (orgs.). O moderno em questão: a década de 1950 no Brasil. Rio de Janeiro: Topbooks, 2008, p. 357-387.

DOSMAN, E. J. Raúl Prebisch (1901-1986): a construção da América Latina e do Terceiro Mundo. Rio de Janeiro: Contraponto, Centro Internacional Celso Furtado, 2011.

FURTADO, C. Economia colonial no Brasil nos séculos XVI e XVII. São Paulo: HUCITEC, ABPHE, 2001 (Tese de Doutorado, 1948).

FURTADO, C. Características gerais da economia brasileira. Revista Brasileira de

Economia. Rio de Janeiro: FGV, ano 4, nº 1, mar. 1950, p. 7-36.

FURTADO, C. A programação do desenvolvimento econômico II. Revista do ConselhoNacional de Economia. Rio de Janeiro, v. 2, nº 19-20, novembro-dezembro 1953, p. 11-15. 
FURTADO, C. A economia brasileira. Rio de Janeiro: Editora A Noite, 1954a.

FURTADO, C. A técnica do planejamento econômico. Revista de Ciências Econômicas da Ordem dos Economistas de São Paulo, ano XI, 70, 1954b, p. 3-13.

FURTADO, C. Uma economia dependente. Rio de Janeiro: Ministério da Educação eCultura, 1956a.

FURTADO, C. Setor privado e poupança. Econômica Brasileira. Rio de Janeiro, v. II, 2,abril-junho 1956b, p. 100-102.

FURTADO, C. Fundamentos da programação econômica. Econômica Brasileira. Rio de Janeiro, v. IV, 1-2, janeiro-junho 1958a, p. 39-44.

FURTADO, C. Perspectivas da economia brasileira. Rio de Janeiro: ISEB, 1958b.

FURTADO, C. Formação econômica do Brasil. 34. ed. São Paulo: Companhia das Letras, 2007 (1959).

FURTADO, C. A pré-revolução brasileira. Rio de Janeiro: Fundo de Cultura, 1962.

FURTADO, C. A fantasia organizada. Rio de Janeiro: Paz e Terra, 1985.

FURTADO, C. A fantasia desfeita. Rio de Janeiro: Paz e Terra, 1989.

Grupo de trabalho para o desenvolvimento do nordeste. Uma política de desenvolvimento econômico para o Nordeste. Rio de Janeiro: Departamento de Imprensa Nacional, 1959.

MANNHEIM, K. O homem e a sociedade. Rio de Janeiro: Zahar Editores, 1962 (1940).

MANNHEIM, K. Liberdade, poder e planificação democrática. São Paulo: Mestre Jou, 1972 (1951).

Plano trienal de desenvolvimento econômico e social 1963- 65. In: FURTADO, R. F. d'A. O Plano Trienal e o Ministério do Planejamento. Rio de Janeiro: Contraponto, Centro Internacional Celso Furtado, 2011 (1962). 